\title{
Sinus node dysfunction during long-term lithium
}

\section{treatment}

\author{
M Rosenqvist, L Bergfeldt, $H$ Aili`, A A Mathé
}

Abstract

Background and objective-Lithium has occasionally been reported to cause symptomatic sinus node bradyarryhthmias. The prevalence and mechanism of these arrhythmias during long-term treatment are unknown. The aims of this study were $(a)$ to evaluate the systemic effects of lithium treatment on cardiac conduction in individuals who were free from cardiovascular disorders; (b) to assess the prevalence of lithium treatment in a group of patients with pacemakers; and (c) to evaluate the interaction between the parasympathetic limb of the autonomous nervous system and the sinus node cells during long-term lithium treatment.

Patients and methods-45 patients who had been treated with lithium for $>12$ months were investigated in a long-term electrocardiography study. Only patients without cardiovascular disease, or concomitant chronotropic medication, or metabolic disorders known to cause rhythm disturbances were included. An age-stratified population was used as a reference group. 21 patients also underwent analysis of carotid sinus pressure and sinus cycle length before and after atropine to clarify whether neural mechanisms were involved. The prevalence of lithium treated patients was determined in 650 patients with pacemakers.

Department of Cardiology, Karolinska Institute, at Karolinska Hospital, Stockholm, Sweden

M Rosenquist

L Bergfeldt

Second Department of Psychiatry,

Karolinska Institute at Huddinge Hospital, Huddinge, Sweden H Aili

Department of Psychiatry,

Karolinska Institute at

St Göran Hospital,

Stockholm, Sweden

A A Mathé

Correspondence to:

Dr Mårten Rosenqvist,

Department of Cardiology,

Thoracic Clinics, Karolinska Hospital, 10401 Stockholm Sweden.

${ }^{\star} \mathrm{Dr} \mathrm{H}$ Aili died on

6 September 1990.

Accepted for publication 4 May 1993 $\mathrm{mmol} / 1>1 \cdot 5$ is usually regarded as a toxic concentration.

$\star$ Symptom related to arrhythmias. node dysfunction (sinus arrest $>1.5 \mathrm{~s}$, minimum heart rate $<50$ beats $/ \mathrm{min}$ ) were found in $56 \%$ and $78 \%$ respectively in the lithium-treated group compared with $30 \%$ and $30 \%$ respectively in the reference group ( $p<0.01)$. Severe sinus node dysfunction was equally common in both groups. (b) The prevalence of chronic lithium treatment in the pacemaker population was $0 \cdot 46 \%$. (c) Sinus cycle variations were abnormal in the basal state in three (14\%) patients and in $11(52 \%)$ patients after atropine despite signs of intact and normal parasympathetic innervation.

Conclusions-Depressed sinus node function was significantly more common in a lithium-treated population than in an age-stratified reference group. Clinically significant dysfunction, however, was uncommon. The effect of lithium on the sinus node seemed to be intrinsic and was not caused by increased parasympathetic tone.

(Br Heart F 1993;70:371-375)

Lithium is commonly used to prevent and treat major affective disorders. Symptomatic sinus node dysfunction has been observed during lithium treatment. In most cases this adverse effect was reversible when lithium medication was stopped but some patients have required permanent pacing (table 1 ).$^{1-15}$ Though there are numerous published case

Table 1 Review of published case reports of bradycardia ascribed wholly or partially to lithium ingestion

\begin{tabular}{|c|c|c|c|c|c|c|c|c|}
\hline $\begin{array}{l}\text { First author } \\
\text { (year) }\end{array}$ & $M / F$ & Age & $\begin{array}{l}\text { Duration } \\
\text { (yr) }\end{array}$ & $\mathrm{Li} / \mathrm{s}$ & Arrhythmia & Reversible & $\begin{array}{l}\text { Latent } \\
\text { SND }\end{array}$ & $E P S$ \\
\hline $\begin{array}{l}\text { Wellens }(75)^{1} \\
\text { Eliasen }(75)^{2} \\
\text { Wilson }(76)^{3} \\
\text { Le Heuzey }(76)^{4} \\
\text { Albrecht }(77)^{5} \\
\text { Constans }(78)^{6} \\
\text { Hagman }(79)^{7}\end{array}$ & $\begin{array}{l}\mathrm{F} \\
\mathbf{M} \\
\mathbf{F} \\
\mathbf{M} \\
\mathbf{F} \\
\mathbf{F} \\
\mathbf{F}\end{array}$ & $\begin{array}{l}56 \\
64 \\
64 \\
66 \\
\text { NA } \\
75 \\
75\end{array}$ & $\begin{array}{c}6 \\
5 \\
7 \\
5 \\
\text { NA } \\
14 \\
2\end{array}$ & $\begin{array}{l}1.0 \\
\text { NA } \\
\text { NA } \\
1.40 \\
0.92 \\
1.5 \\
\text { NA }\end{array}$ & $\begin{array}{l}\text { SB 45, SP } 3 \mathrm{~s}^{\star} \\
\text { SB 20, SP } 4 \mathrm{~s}^{\star} \\
\text { SB 35, SP } 4 \cdot 6 \mathrm{~s} \\
\text { SB 33, JB } 34 \\
\text { SB 42 } \\
\text { SP > } 3 \mathrm{~s}^{\star} \\
\text { SB 35, SP } 5 \mathrm{~s}, \\
\text { JB, SVT, VT* }\end{array}$ & $\begin{array}{l}\text { Yes } \\
\text { Yes } \\
\text { Yes } \\
\text { No } \\
\text { NA } \\
\text { Yes } \\
\text { Yes }\end{array}$ & $\begin{array}{l}\text { No } \\
\text { No } \\
\text { No } \\
\text { NA } \\
\text { NA } \\
\text { No } \\
\text { Yes }\end{array}$ & $\begin{array}{c}\times 2 \\
\mathrm{NA} \\
\times 2 \\
\times 1 \\
\mathrm{NA} \\
\times 1 \\
\times 1\end{array}$ \\
\hline $\begin{array}{l}\text { Bigger }(79)^{8} \\
\text { Rector }(79)^{9} \\
\text { Roose }(79)^{10} \\
\text { Wong }(81)^{11} \\
\text { Palileo }(83)^{12} \\
\text { Rodney }(83)^{13} \\
\text { Weintraub }(83)^{14} \\
\text { Montalescot }(84)^{15}\end{array}$ & $\begin{array}{l}\mathrm{M} \\
\mathbf{N A} \\
\mathrm{F} \\
\mathrm{F} \\
\mathbf{M} \\
\mathrm{M} \\
\mathrm{F} \\
\mathrm{M} \\
\mathrm{M}\end{array}$ & $\begin{array}{l}63 \\
\text { NA } \\
60 \\
53 \\
57 \\
61 \\
59 \\
60 \\
56\end{array}$ & $\begin{array}{l}6 \\
\text { NA } \\
2 \\
3 \text { month } \\
4 \\
1 \text { wk } \\
3 \\
5 \\
12\end{array}$ & $\begin{array}{l}1 \cdot 1 \\
\text { NA } \\
0 \cdot 8 \\
0 \cdot 7 \\
1 \cdot 46 \\
0 \cdot 7 \\
1 \cdot 3 \\
1 \cdot 2 \\
0 \cdot 8\end{array}$ & $\begin{array}{l}\text { SB } 20, \text { SP } 10 \mathrm{~s}^{\star} \\
\text { SP } \\
\text { SB } 33, \text { SP } \\
\text { SP } 1.6 \mathrm{~s}, \mathrm{Jesc} \\
\text { TBS, SP } 9 \mathrm{~s}^{\star} \\
\text { SB }{ }^{\star} \text { (after } 1 \mathrm{yr} \text { ) } \\
\text { SP } 2 \cdot 9 \mathrm{~s}, \mathrm{JB} 30 \\
\text { SB } 36^{\star} \\
\text { SB } 25^{\star}\end{array}$ & $\begin{array}{l}\text { Yes } \\
\text { Partial } \\
\text { NA } \\
\text { Yes } \\
\text { Yes } \\
\text { Yes } \\
\text { Partial } \\
\text { Yes } \\
\text { Yes }\end{array}$ & $\begin{array}{l}\text { No } \\
\text { Yes } \\
\text { NA } \\
\text { No } \\
\text { AMI } \\
\text { Yes? } \\
\text { Yes } \\
\text { NA } \\
\text { No }\end{array}$ & $\begin{array}{l}\times 2 \\
\times 2 \\
\times 1 \\
\mathrm{NA} \\
\times 1 \\
\times 3 \\
\mathrm{NA} \\
\mathrm{NA} \\
\times 2\end{array}$ \\
\hline
\end{tabular}

AMI, acute myocardial infarction; EPS, electrophysiological study; JB, junctional bradycardia; Jesc, junctional escape rhythm; NA, not available; SB, sinus bradycardia (beats/min); SP, sinus pause; SND, sinus node dysfunction; SVT, supraventricular tachycardia; TBS, tachycardia bradycardia syndrome; VT, ventricular tachycardia. Lithium concentrations either in meq/l or 
reports, there are no data on the frequency and severity of bradyarrhythmias in a lithiumtreated population. Because symptoms of dizziness and syncope are difficult to evaluate in patients with psychiatric illness they may be overlooked and episodes of significant bradycardia induced by lithium might be underestimated. Conversely, there is no information available on the prevalence of lithium treatment in patients with a pacemaker. Nor is it clear whether the lithium-induced impairment of sinus node function is the result of a direct effect on the sinus node or is mediated by neural changes.

The aims of the present study were $(a)$ to evaluate the systemic effects of lithium treatment on cardiac conduction in individuals free from cardiovascular disorders, (b) to assess the prevalence of lithium treatment in large group of patients with pacemakers; $(c)$ to evaluate the interaction between the parasympathetic limb of the autonomous nervous system and the sinus node cells during long-term lithium treatment.

\section{Patients and methods \\ PATIENTS}

Fifty patients who had been treated with lithium for at least 12 months were recruited from two hospitals in the Stockholm County area from a pool of 255 patients (mean age 53 years, $58 \%$ females) on long-term lithium treatment. We excluded patients who were treated with cardioactive or psychotropic drugs with chronotropic effects. All of the patients who were included were considered to be in a stable psychiatric and metabolic condition. None of the patients had had their lithium dose changed in the four months preceding the trial. No patient had any clinical signs of lithium intoxication at the time of the study. None of the patients had any known cardiovascular disease. All patients were in sinus rhythm and their 12 lead electrocardiograms did not show any signs of atrioventricular block or previous myocardial infarction. Patients had 24 hour electrocardiographic monitoring performed as an outpatient recording. Patients were asked to keep a diary and note symptoms of dizziness or syncope. Blood samples for analysis of thyroid hormone, kidney function and electrolytes were drawn when electrocardiograms were recorded. Serum lithium concentration was also measured.

\section{LONG-TERM ELECTROCARDIOGRAPHIC RECORDINGS}

Long-term ECG recordings were performed as an ambulatory out-of-hospital procedure and recorded on a Medilog two channel FM tape recorder (Reynold Tracker, Oxford).

The recordings were analysed by a computer-assisted system $^{16}$; all recordings were checked manually, however. Only pauses $\geqslant 1.5 \mathrm{~s}$ were noted. Minimal heart rate was calculated from two consecutive RR intervals including the longest pause during day
(07 00-00 00) and night $(0000-0700)$ as described by Bjerregaard. ${ }^{17}$

\section{REFERENCE POPULATION}

The population, (260 healthy individuals aged 40-79) described by Bjerregaard ${ }^{17}$, was used to supply normal values in an age-stratified population. The degree of sinus node dysfunction was defined as follows: moderate sinus bradycardia, $<50$ but $\geqslant 40$ beats/min; marked sinus bradycardia, $<40$ beats $/ \mathrm{min}$. Sinus pauses were divided into three subgroups: $\geqslant 1500 \mathrm{~ms}$, $\geqslant 1750 \mathrm{~ms}$, and $\geqslant 2000$ ms.

SINUS CYCLE VARIATION AND

PARASYMPATHETIC INFLUENCE

The function of the sinus node and its parasympathetic innervation were evaluated in a subset of the study group. The sinus cycle variations were assessed during one minute electrocardiographic recordings at a paper speed of $50 \mathrm{~mm} / \mathrm{s}$. The patients were requested to close their eyes and relax as much as possible while breathing at a normal rate and depth. The sinus cycle variations were calculated according to previously described methods. ${ }^{1819}$ The range of variation was expressed as a percentage of mean sinus cycle length, and the maximal difference between any two consecutive sinus cycle lengths (the maxdelta) was expressed in ms. The observed values were compared with age-stratified reference values from 75 healthy subjects. ${ }^{19}$

Carotid sinus pressure was then applied for 10 seconds twice on each side after carotid bruits had been excluded by auscultation. The maximal sinus cycle length during carotid sinus pressure was measured and compared with the mean of five sinus cycle lengths measured immediately before carotid sinus pressure at a paper speed $50 \mathrm{~mm} / \mathrm{s}$. Atropine was then given as an intravenous bolus injection of $0.04 \mathrm{mg}$ per $\mathrm{kg}$ body weight over 30 seconds. After three minutes a new one minute recording for analysis of sinus cycle variation was obtained and carotid sinus pressure was then reapplied.

\section{PACEMAKER POPULATION STUDY}

We assessed the prevalence of patients on continuous ( $>12$ months) lithium treatment by reviewing records from our pacemaker population. During a five year period 650 patients from a catchment area of 650000 inhabitants had a permanent pacemaker implanted because of symptomatic bradyarrhythmias.

\section{STATISTICAL ANALYSIS}

Data are given as mean (SD) unless stated otherwise. The unpaired Students' $t$ test was used to determine differences between groups and $\chi^{2}$ analysis was used to test for differences in proportions. A probability of $<0.05$ was considered statistically significant.

The prospective part of this study was approved by the local ethics committee and patients gave their informed consent. 
Table 2 Clinical and biochemical characteristics of the 45 patients and the reference population

\begin{tabular}{lc}
\hline Characteristic & Value \\
\hline Patients (45): & \\
Females & $62 \%$ \\
Age & $50 \cdot 4(10)(34-72) \mathrm{yr}$ \\
Duration of treatment & $82(60)(12-240) \mathrm{mnth}$ \\
Thyroxine substitution & $16 \%$ \\
Lithium concentration & $0 \cdot 66(0 \cdot 1)(0 \cdot 4-0 \cdot 9) \mathrm{mmo} / 1$ \\
Potassium & $4 \cdot 4(0 \cdot 3)(3 \cdot 9-5 \cdot 1) \mathrm{mmol} /$ \\
Creatinine & $84(17)(58-141) \mu \mathrm{mol} / 1$ \\
Normal serum calcium & $100 \%$ \\
Normal thyroid stimulating hormone concentration & $96 \%$ \\
Reference population & \\
Mean age $(260):$ & $54 \cdot 3(40-79) \mathrm{years}$ \\
Females & $35 \%$ \\
Reference values: & $0 \cdot 5-1 \cdot 3 \mathrm{mmol} / 1$ \\
Lithium & $<115 \mu \mathrm{mol} / 1$ \\
Creatinine & $3 \cdot 4-5 \cdot 2 \mathrm{mmol} / 1$ \\
Potassium & \\
\hline
\end{tabular}

\begin{abstract}
Results
PATIENT POPULATION

Table 2 shows the clinical characteristics of the patients. All the patients had therapeutic or sub-therapeutic lithium concentrations in serum. Two patients with subtherapeutic lithium concentrations $(0.3$ and $0.4 \mathrm{mmol} / 1$, therapeutic range $0.5-1.3 \mathrm{mmol} / \mathrm{l})$ were included because the suboptimal serum concentrations had a good clinical effect. One patient with a slightly raised concentration of thyroid stimulating hormone was included because this spontaneously became normal four weeks later. One patient had signs of a moderate kidney dysfunction. All patients had normal serum potassium concentrations.
\end{abstract}

\section{LONG-TERM ECG}

Five patients were excluded from analysis because of unsatisfactory electrocardiographic recording quality. Thus 45 patients were included for final evaluation. Table 3 shows the prevalence of sinus node dysfunction as recorded on a long-term electrocardiogram in the lithium treated population. During the night the lowest heart rate was 33 beats/min and during the day it was 37 beats $/ \mathrm{min}$. The maximum sinus pause was $1.7 \mathrm{~s}$ during the day and $2 \cdot 1 \mathrm{~s}$ during the night. In 33 patients $(73 \%)$ the lowest heart rate occurred during day time whereas in nine patients it occurred during the night. In three patients there was no difference between day and night. No symptoms related to bradycardia were noted during the recording period. The mean age for the nine patients with heart rates below 40 beats/min or sinus pauses $>1.5 \mathrm{~s}$ was 52.3 years; this was not significantly different from

Table 3 Results from long-term ECG monitoring of patients compared with the reference group

\begin{tabular}{lcll}
\hline & $\begin{array}{l}\text { Present study }(n=45) \\
n(\%)\end{array}$ & $\begin{array}{l}\text { Bjerregaard }(n=260)^{17} \\
n(\%)\end{array}$ & $p$ \\
\hline Bradycardia: & & & \\
HR $<50$ beats/min & $34(78)$ & $77(29 \cdot 6)$ & $<0.05$ \\
HR $<40$ beats/min & $5(11)$ & $24(9 \cdot 2)$ & NS \\
Pauses: & $25(56)$ & $77(30)$ & $<0.01$ \\
$\geqslant 1.5 \mathrm{~s}$ & $3(6 \cdot 6)$ & $12(4 \cdot 6)$ & $\mathrm{NS}$ \\
$\geqslant 1.75 \mathrm{~s}$ & $1(2 \cdot 2)$ & $2(0.7)$ & $\mathrm{NS}$ \\
$\geqslant 2.0 \mathrm{~s}$ & & & \\
\hline
\end{tabular}

the rest of the study population.

SINUS CYCLE VARIATION AND

PARASYMPATHETIC INTERACTION

Twenty one patients were studied ( 15 women and six men mean age of 46 years (34-61)). Their mean basic heart rate was 68 beats $/ \mathrm{min}$ (50-96). All patients had a normal 12 lead electrocardiogram. The sinus cycle variations in the basal state were within reference limits in 18 patients (86\%), two had an increased maxdelta ( $>3 \mathrm{SD}$ in one, and $>6 \mathrm{SD}$ in the other), and the remaining patient had both increased variation range and maxdelta, which is highly suggestive of sinus node dysfunction. ${ }^{19}$

Carotid sinus pressure $(n=20)$ induced a mean maximal increase of $19 \%$ in the sinus cycle length (SD 12\%; 5-51\%). The maximum increase in any one patient was $394 \mathrm{~ms}$; however, no sinus cycle length exceeded $1 \cdot 3 \mathrm{~s}$. Atropine induced a mean increase in heart rate of 30 beats/min (to a mean heart rate of 98 beats $/ \mathrm{min}$ ) corresponding to an increase of $+45 \%$ (SD 9 beats $/ \mathrm{min} ; 15-53$ beats $/ \mathrm{min}$ ). Carotid sinus pressure induced a mean increase of $2 \cdot 8 \%$ after atropine, indicating almost complete vagolysis. In conjunction with this observation maxdeltas were decreased in all patients. However, the variation range was reduced to the expected degree in only 10 of the patients, while the remaining 11 showed a greater variation range after atropine than was expected.

\section{PREVALENCE OF LITHIUM TREATMENT IN} PATIENTS WITH PACEMAKERS

Three patients on long-term lithium treatment, a prevalence of $0.46 \%$, were found in our pacemaker population, corresponding to an annual incidence of $0.05 \%$. These were two women and one man aged 56, 64, and 72 years respectively. All patients had been treated with lithium for between 10 and 30 years. They all had therapeutic serum concentrations of lithium when cardiac symptoms were present. In all patients, signs of sinus node disease with heart rates of 28-45 beats/min and pauses of between 2.5 and $3.8 \mathrm{~s}$ were registered. In one patient an electrophysiological study was performed after lithium had been discontinued: it showed signs of persistent impairment of sinus node function. All three patients were given permanent pacemakers and became free of symptoms.

\section{Discussion}

The results from the present study indicate that depressed sinus node function was significantly more common in a lithium-treated population than in an age-stratified reference group. Clinically significant dysfunction, however, seems to be uncommon because we found a prevalence of only $0.46 \%$ of lithium treatment in a pacemaker population. Finally the effect of lithium on the sinus node seems to be intrinsic and not the result of increased parasympathetic tone. 
PREVIOUS REPORTS AND CLINICAL IMPLICATIONS

Despite numerous case reports describing patients with sinus node dysfunction caused by lithium treatment (table 1) few studies have tried to estimate the prevalence of lithium-induced sinus node dysfunction.

Tilkian et al ${ }^{20}$ studied 12 patients by 12 lead electrocardiography, an exercise test, and $24 \mathrm{~h}$ electrocardiographic recording before and 6-14 days after the start of lithium therapy. Though they observed slight chronotropic incompetence on exercise during lithium treatment they did not find any signs of sinus node dysfunction during $24 \mathrm{~h}$ ECG monitoring. It could be that the patients were studied too soon after the start of lithium treatment. In most of the case reports describing sinus node dysfunction during lithium treatment the patients had been treated for much longer. We only studied patients who had taken lithium for at least 12 months.

Hagman et $a l^{7}$ used 12 lead electrocardiography and carotid message to study 97 consecutive patients on long-term lithium treatment. Prolonged asystole ( $>3 \mathrm{~s}$ ) owing to sinus node dysfunction or high grade atrioventricular block was seen during carotid massage in three symptom free patients, and was considered to be caused by lithium treatment. Whether asystole of $>3 \mathrm{~s}$ during carotid massage in otherwise symptom free individuals indicates the presence of a conduction system disorder is controversial. Berglund et al reported on nine healthy individuals, three of whom had asystole of more than $3 \mathrm{~s}$ during carotid pressure. ${ }^{21}$ These subjects had completely normal Holter recordings and remained symptom free over a three year follow up. Bucht et al prospectively studied, with 12 lead electrocardiogram, 53 patients before and 4-12 months after the start of lithium treatment. ${ }^{22}$ Except for a significant decrease in resting heart rate during lithium treatment no signs of sinus node dysfunction were reported. The low sensitivity of the 12 lead electrocardiogram in detecting sinus node dysfunction might explain these results.

Though we found that in a lithium treated population sinus node dysfunction was about twice as common as expected we did not detect an increased prevalence of clinically significant dysfunction. Thus, severe sinus node disease in association with lithium treatment is probably uncommon: this is reflected by the low prevalence $(<0.5 \%)$ of lithium treated patients in the pacemaker population. The hypothesis that symptomatic sinus node dysfunction could be underestimated among lithium-treated patients is therefore unlikely. It seems reasonable to postulate that the effect of lithium on the sinus node might only become clinically important in patients with latent sinus node dysfunction. We reviewed published reports on lithium-induced sinus node dysfunction in patients not taking concomitant chronotropic medication and without lithium intoxication (table 1). We found
16 case reports and most of the patients showed complete or partial regression of the conduction disorder after lithium treatment stopped. Latent sinus node disease was suspected or confirmed in only three cases. It thus seems that lithium is able to induce clinically significant but reversible dysfunction in individuals with an otherwise normal sinus node.

None the less a pre-existing or latent sinus node disturbance may predispose to clinically important sinus node disease if lithium treatment is started. This suggestion is supported by the fact that patients who had sinus node dysfunction during lithium treatment including our own three patients were significantly older (63 (7) years) than our reference study population. This age group is also more typical of patients with clinical signs of sinus node disease. ${ }^{23}$

\section{MECHANISM}

The mechanism by which lithium depresses sinus node function is not fully understood. Animal experiments indicate that lithium depresses the intracellular potassium concentration. In addition lithium replaces intracellular calcium. ${ }^{24}$ These disturbances seem to induce various electrophysiological changes including a decrease of the depolarisation rate and reduced electrical impulse propagation. ${ }^{25}$

In our study carotid sinus pressure showed the sinus node depolarisation rate, but not to the extent where it became abnormal. This implies intact innervation and absence of carotid sinus hypersensitivity. Absence of such hypersensitivity is contrary to the suggestion of Hagman et al. ${ }^{7}$ The relative response to atropine resembled the $46 \%$ increase observed by Alboni et al ${ }^{26}$ though their 20 healthy subjects had a slightly higher basic heart rate (76 v 68 beats $/ \mathrm{min}$ ), and reached a higher rate after atropine $(111 v 98$ beats/min). These results are also consistent with intact and normal parasympathetic innervation. Furthermore, they are consistent with the experimental data showing depolarisation at an increased time constant. It has also been suggested that lithium might decrease the sensitivity of the sinus node to sympathetic stimulation. ${ }^{27}$ Because the functional state after atropine reflects an unopposed sympathetic influence, the observed "normal" response to this drug in our study implies that the $\beta$ receptor sensitivity was unimpaired in our patients. The fact that episodes of bradycardia were more common during daytime-that is, they had non-circadian pattern despite an intact parasympathetic system-adds additional support to findings from animal data suggesting that lithium acts on the sinus node itself and not its nerve supply. ${ }^{8}$ Our data suggest that longterm lithium treatment changes the ionic milieu within the spontaneously depolarising sinus node cells even at therapeutic concentrations. It is not known whether or not a single ionic current is responsible for the depolarisation of the sinus node cells. Interaction between lithium and several currents 
such as $\mathrm{IK}, \mathrm{ICa}$, the $\mathrm{Na} / \mathrm{Ca}$ exchange current, and a N/K pump current might lead to the observed results. ${ }^{28}$

\section{LIMITATIONS OF THE STUDY}

The reference group used in this study was not individually matched to the study group. Instead we used an age stratified reference population from another hospital. ${ }^{17}$ The proportion of females was higher in the study group than in the reference population. Though these groups were not strictly comparable, we do not consider that this significantly influenced our results. The study population was screened for absence of cardiovascular disorders and was not taking cardioactive drugs. The present results should be applied only to patients meeting these criteria. This study was supported by the Research Funds of the
Karolinska Institute and the Swedish Heart and Lung Foundation.

1 Wellens HJ, Cats VM, Düren DR. Symptomatic sinus node abnormalities following lithium carbonate therapy. Am f Med 1975;59:285-7.

2 Eliasen P, Andersen M. Sinoatrial block during lithium treatment. Eur f Cardiol 1975;33:97-8.

3 Wilson JR, Kraus ES, Bailas MM, Rakita L. Reversible sinus node abnormalities due to lithium carbonate therapy. N Engl $\mathcal{F}$ Med 1976;294:1223-4.

4 Le Heuzey JY, Degusseau B, Belliard JP, Soulié J, Grivaux M. Dysfonctionnement sinusal troubles de conduction étages et intoxication par le lithium. Sem hop duction étages et int
Paris 1976;54:303-6.

5 Albrecht J, Müller-Oerlinghausen B. EKG-Veränderungen unter akuter und chronischer applikation von Lithium. Pharmacopsychiatry 1977;10:325-33.

6 Constans R, Chapelet A, Marco J, Dardennel P. Dysfonctionnement sinusal reversible au cours dún traitment par le carbonate de lithium. Acta Cardiologica 1978;5:315-22.

7 Hagman A, Arnman K, Rydén L. Syncope caused by lithium treatment. Acta Med Scand 1979;205:467-71.

8 Bigger JT, Reiffel JA. Sick sinus syndrome. Annu Rev Med 1979;30:91-118
9 Rector WG, Jarzobski JA, Levin HS. Sinus node dysfunction associated with lithium therapy. Nebr Med $\mathcal{F} 1979$; 19:193-6.

10 Roose SP, Nurnberger II, Dunner DL, Blood DK, Fieve RR. Cardiac sinus node dysfunction during lithium

11 Wong KC. Tachy-bradycardia syndrome related to lithium therapy. Can Med Assoc $\mathcal{F} 1981 ; 124: 1324$.

12 Palileo EV, Coelho A, Westveer D, Dhingra R Rosen KM. Persistent sinus node dysfunction secondary to lithium therapy. Am Heart $\mathcal{F}$ 1983;106:1443-4.

13 Rodney VM, Chopivsky P, Hara JH. Lithium-induced dysrhythmias as a marker for sick sinus syndrome. $\mathscr{f}$ Fam Pract 1983;16:797-9.

14 Weintraub $M$, Hes JP, Rotmensch $\mathrm{HH}$, Soferman G, Liron M. Extreme sinus bradycardia associated with lithium therapy. Isr $\mathcal{F}$ Med Sci 1983;19:353-5.

15 Montalescot G, Levy Y, Fargé D, Brochard L, Fantin B, Arnoux $C$. Lithium causing serious sinus node dysfuncArnoux C. Lithium causing serio

16 Nygårds M-E, Ahrén T, Tranesjö J, Wigertz O. A computer program for analysis of long-term ECG. Comput Cardiol 1979;6:429-32.

17 Bjerregaard P. Mean 24 hour heart rate, minimal heart rate and pauses in healthy subjects 40-79 years of age. Eur Heart $\mathcal{f} 1983 ; 4: 44-51$.

18 Persson A, Solders G. R-R variations, a test of autonomic dysfunction. Acta Neurol Scand 1983;67:285-93.

19 Bergfeldt BL, Edhag KO, Solders G, Vallin HO. Analysis of sinus cycle variation a new method for evaluation of suspected sinus node dysfunction. Am Heart $\mathcal{F} 1987$ 114:321-7.

20 Tilkian AG, Schroeder JS, Kao J, Hultoren H. Effect of lithium on cardiovascular performance: Report on lithium on cardiovascular performance: Report on before and during lithium therapy. $\mathrm{Am} \mathcal{F}$ Cardiol before and durin

21 Berglund $\mathrm{H}$, Rosenqvist $M$, Boukter $S$, Bevegård $S$, Edhag KO. Responses to carotid sinus stimulation before and after propranolol. Br Heart $\mathcal{f}$ 1988;60: 516-21.

22 Bucht G, Smigan L, Eriksson P. ECG changes during lithium therapy-a prospective study. Acta Med Scand 1984;216:101-4.

23 Sutton R, Kenny R-A. The natural history of sinus node disease. PACE 1986;9(suppl II):1110-4

24 El-Mallakh RS. The ionic mechanism of lithium action. Lithium 1990;1:87-92

25 Singer I, Rotenberg D. Mechanisms of lithium action. $N$ Engl f Med 1973;289:254-60.

26 Alboni P, Malcarne C, Pedroni C, Masoni A, Narula OS Electrophysiology of normal sinus node function with and without autonomic blockade. Circulation 1982;65: 1236-42.

27 Fenn WE, Davis JM, Janowsky, Cavanaugh JH, Kausmann JS, Griffith JD. Effects of lithium on adrenergic function in man. Clin Pharmacol Ther 1972;13: $71-6$.

28 Irisawa $H$, Giles WR. Sinus and atrioventricular node cells: Cellular electrophysiology. In: Zipes DP, Jalife J eds. Cardiac electrophysiology. From cell to bedside. Philadelphia: WB Saunders 1990;95-102. 